Tolmer C-E. and Castaing C. (2017). "Applying system and requirement engineering for information modelling in infrastructure projects." In: LC3 2017: Volume I - Proceedings of the Joint Conference on Computing in Construction (JC3), July 4-7, 2017, Heraklion, Greece, pp. 329-336. DOI: https://doi.org/10.24928/JC3-2017/0296.

\title{
APPLYING SYSTEM AND REQUIREMENT ENGINEERING FOR INFORMATION MODELING IN INFRASTRUCTURE PROJECTS
}

\author{
Charles-Edouard Tolmer ${ }^{1}$, Christophe Castaing ${ }^{2}$
}

\begin{abstract}
The definition of LOD is currently subject of debate: Level Of Detail, Development, Definition, Information, etc. The question of the content of each LOD is generally discussed but much less the question of the real utility of these LOD. We first propose to apply system engineering on the whole project process documentation to identify the BIM uses scope. We then use requirement engineering to validate that modelling information is depending on requirement management. We complete this work with experimentation, applying system and requirement engineering on a specific system, longitudinal drainage system, defining this way a specific BIM use. This experiment complements our conceptual proposal for organizing process requirements related to project information management.
\end{abstract}

Keywords: system engineering, requirement engineering, information management, infrastructure project, BIM.

\section{INTRODUCTION}

Now that BIM is globally accepted, the concepts and methodological tools are progressing. Generally, BIM guides are used to draw up the project BIM Execution Plan (BEP). For the design phase, the best-known are the PAS 1192 (PAS 1192-2 2013) and the BIM project execution planning guide (Penn State 2011). They facilitate the implementation of BIM processes and project organization. The latter are to be defined in coherence with the other classical production processes. Several other guides exist: they cannot all be cited here.

Today, standardisation organisations such as ISO are already considering the BEP guide standardisation. The next standard to go out will probably be the ISO 19650 Information management using building information modelling. This standard contains mainly elements from PAS 1192. However, it does not sufficiently address the concept of BIM use ${ }^{3}$, more present in the PennState Guide (Penn State 2011).

To define BIM use content, we should define the organisation between BIM use, IDM, MVD and also how the level of detail can help to define the relevant information considered with these three conceptual tools.

1 Ph.D. in Urban Engineering, Egis, Project management department. St Quentin en Yvelines, France. Email: charles-edouard.tolmer@egis.fr

2 Director of Numeric engineering program, Egis, St Quentin en Yvelines, France.

Email: christophe.castaing@egis.fr

${ }^{3}$ BIM uses have to be defined not to change the project but only the way the project is made and the way to use BIM efficiently (Kreider \& Messner, 2015). 


\section{METHOD}

\subsection{The issues of LOX}

Answering the question of level of information or detail is still based on generic approaches. In construction industry, a lot of similar but not compliant definitions of LOD (Level Of Detail or Development) exist as explained in (Bolpagni, Luigi and Ciribini 2016). Considering geospatial information, which is necessary for infrastructure projects, we have to add the CityGML LOD definition. This complicates even more the subject (Tolmer 2016). We think that the question about $\mathrm{LOX}^{4}$ is misplaced. The LOX are first of all the answer to help to describe the information exchange requirements and to organise the way to improve the quantity and the quality of information through project phases. Thus, we propose to use requirement engineering, and therefore necessarily system engineering, to identify the requirements and functionality LOX have to help to achieve in information exchanges and structuration.

\subsection{Applying system and requirement engineering}

To define the exchange information, we often begin by asking ourselves what level of detail of the information has to be created and exchanged. Some preliminary steps are needed to properly accomplish this definition work. It is necessary to consider the requirements to be met by the project (Krob 2009; Tarandi 2011; Tolmer and Castaing 2016). Then only the level question and information modelling can be asked.

To this end, we propose to use requirement engineering ${ }^{5}$, and therefore necessarily system engineering which provides a conceptual framework for the application of requirements engineering (Badreau and Boulanger 2014; Fiorèse and Meinadier 2012; Kotonya \& Sommerville, 1998).

It should be noted that to our knowledge, there is no work applying system engineering in the construction industry.

System engineering well separates the project-system that creates the product-system as shown in Figure 1. Needs are defined in the contract and in regulation. A system consists of a set of elements whose synergy is organized to meet a goal in a given environment (Fiorèse and Meinadier 2012).

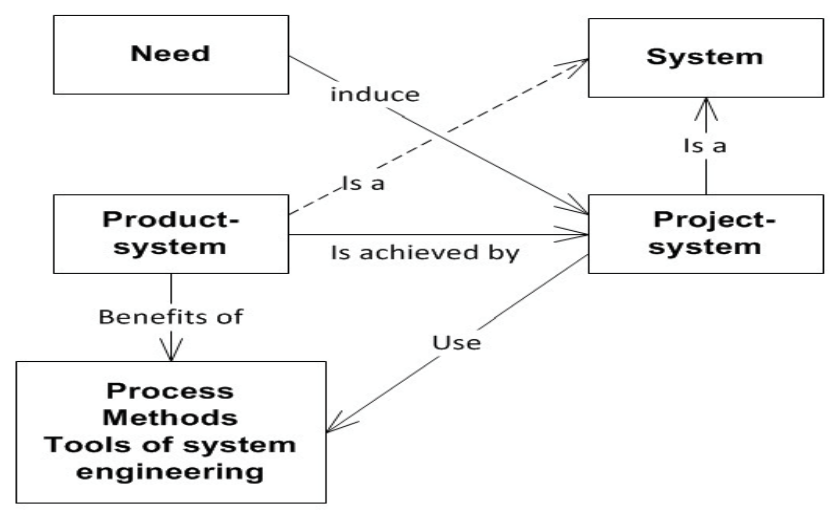

Figure 1: proposed application of System engineering by (Fiorèse and Meinadier 2012).

\footnotetext{
${ }^{4}$ This notation include all forms of Level Of X: detail, development, information, abstraction,...

${ }^{5}$ Requirements engineering refers to the process of defining, documenting and maintaining requirements to the sub-fields of systems engineering (Kotonya \& Sommerville, 1998).
} 
System engineering also need to apply an approach in three visions defined to well distinguish the studied system and the external systems influence it (see Table 1).

Then we use an application of system engineering on all the elements structuring the BIM in a project. As shown in Figure 2. It shows the BIM uses domains. A BIM use integrates product and process requirements, but also the relevant information and its modelling (its LOX in fact).

Table 1: The three visions of system engineering. Adapted of (Krob 2009) for infrastructure project.

\begin{tabular}{ccc}
\hline Vision & Question & Example \\
\hline Operational & Why? & Traffic speed, environmental constraint \\
Functional & What to do? & Inform real-time users of traffic status \\
Organic & How to do? & Class of resistance of a safety barrier \\
\hline
\end{tabular}

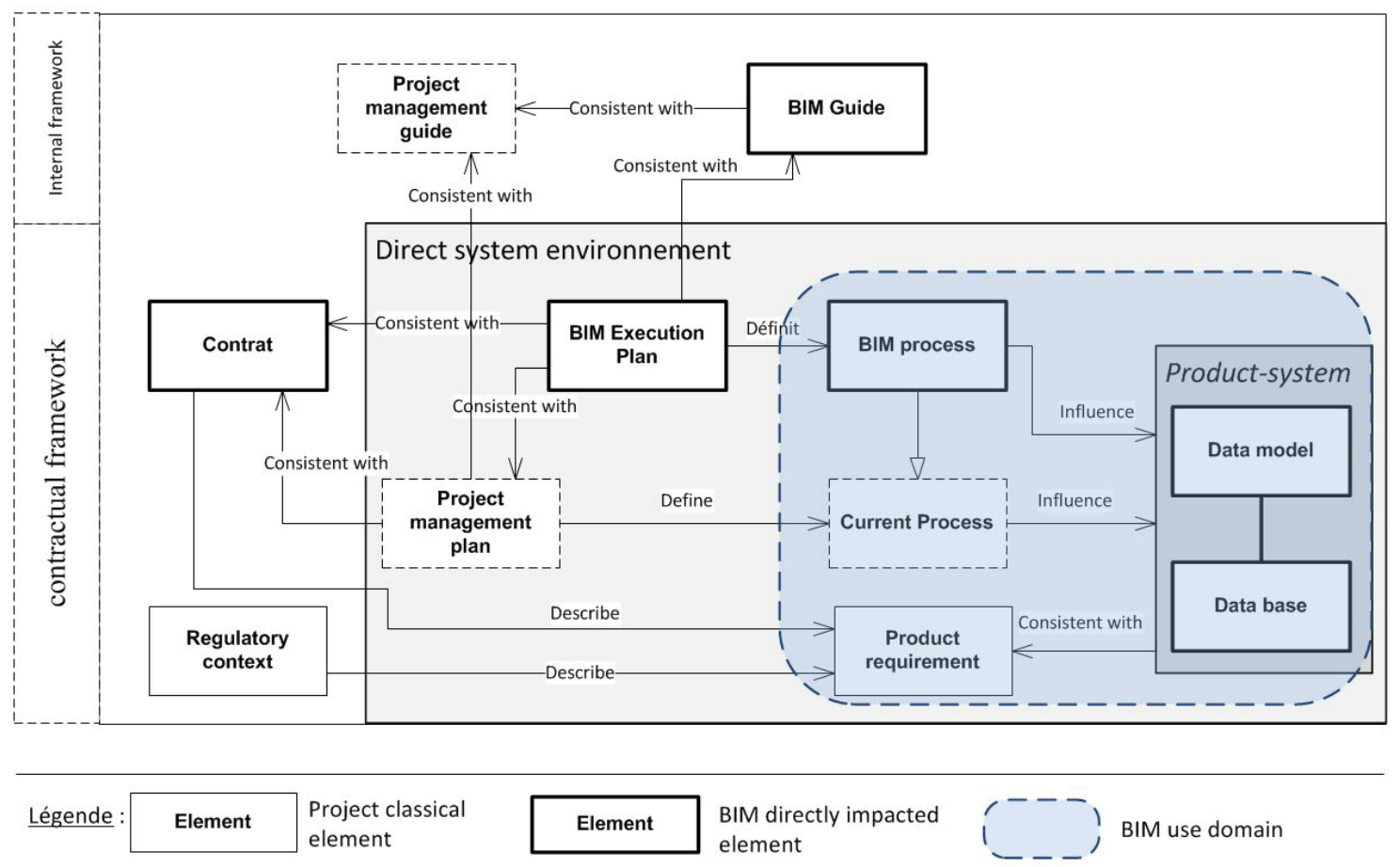

Figure 2: applying system engineering on project system in an infrastructure project.

\subsection{Three stages for information modelling}

Requirements engineering allows defining relevant information and its relevant modelling helping to reach project needs. To have a strong methodology to answer the question on information modelling, we propose to use a three steps modelling process based on (Bouzeghoub 2006), in addition to system and requirement engineering.

In the first step, semantic and domain ontology are selected accordingto the identified requirements concerned by a specific BIM use. For each BIM uses (and for each requirement or small group of requirements), this first step allows in the second 
step to define an abstraction of the project, specific to the BIM use (Let us recall that the abstractions of different BIM uses are partly common.) It also describes partially the content of relative IDM, according to (ISO 29481-1:2016 2016; ISO 29481-2 2012). The second step allows building the conceptual data model for this BIM use. The third step consists in identifying the most appropriate format or way to exchange the information described in step two: it is the support for information exchanges and help to describe MVD (see Figure 3).

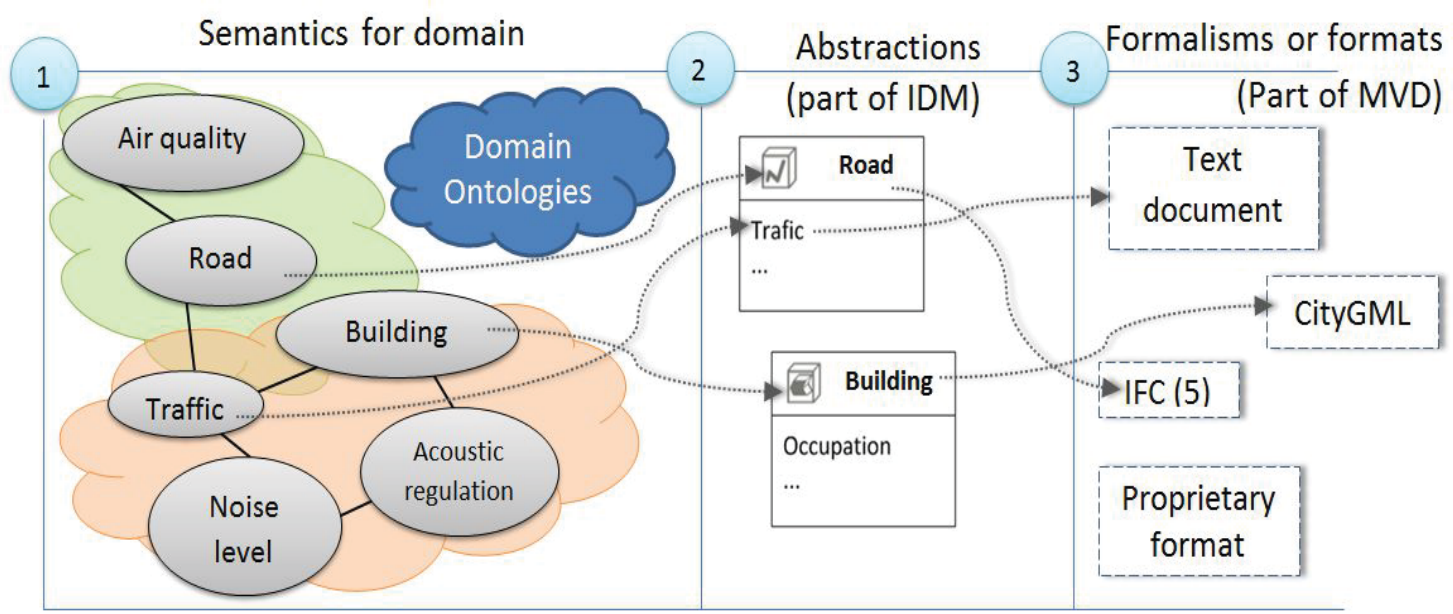

Figure 3: a three steps modelling process based on (Bouzeghoub 2006).

\subsection{Experimentation}

We have tested our proposals on a concrete case. We studied the longitudinal drainage system for road infrastructure. This system is at the interface of many domains and therefore it is concerned by many requirements.

In this work, we tested if:

- system engineering is actually applicable on infrastructure projects and not only on manufacturing industry;

- applying system and requirement engineering makes it possible to achieve to the definition of the contents of a BIM use (and therefore of IDM and MVD) for a specific system.

This work, with bottom-up approach, needs to be completed on more cases and systems to be generalized.

\section{RESULTS}

\subsection{Applicability of system engineering on the project process organisation}

We applied system engineering to the whole process of the design project. We used the concept of level of abstraction (LOA) and the couple LOD-LOI (similar to the (PAS 11922 2013)), proposed in (Tolmer 2016). It represents the first two steps of the Figure 3. Using the system engineering concepts (project system, product system, system environment, process and product requirements, etc.) we come to propose the conceptual model in Figure 4. It shows the integration of system engineering concepts in the BIM classical organisation. 


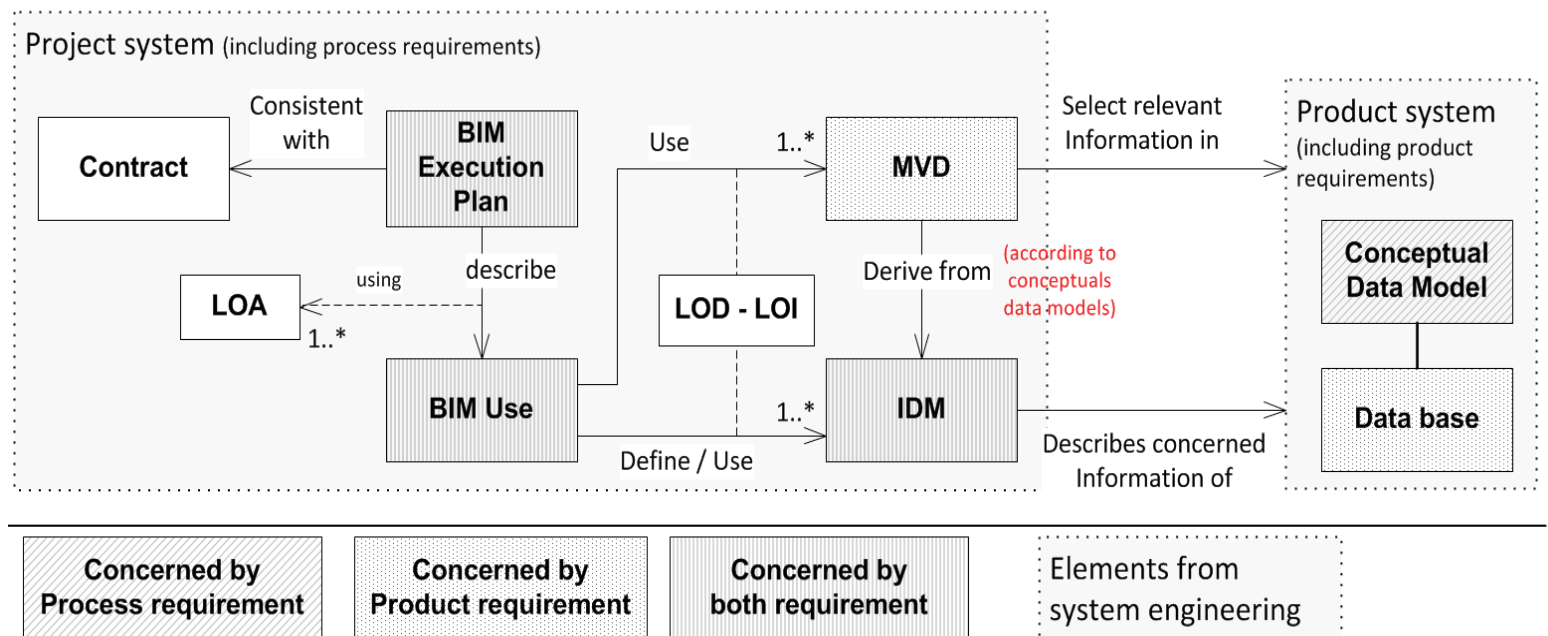

Figure 4: including system engineering concepts in a classical BIM project organisation.

This Figure structures the following steps:

1 - Define the requirements to achieve in the BIM use, considering one or more abstractions (LOA);

2 - Define or use one or more IDM to achieve this BIM use;

3 - Define or select one or more MVD to achieve each IDM of the BIM use, using LOI and LOD.

\subsection{Impact of system and requirements engineering on object breakdown structure}

We apply system engineering to the longitudinal drainage system. We describe for it the three system engineering visions defined above. The first one, operational vision, is about the environment of the studied system. Applying system engineering allows identifying these stakeholders: natural waterway, retention pond and maintenance for simple example (see Figure 5).

We propose a part of our analysis in the Table 2. We describe a need for each external system. We then declare the operational requirement related to the watershed from a functional and organic vision. We have to note that we have made choices in the spatial and functional decomposition of the project for the management of information for this drainage system use case. It remains to be confirmed that these decompositions work for other trades.

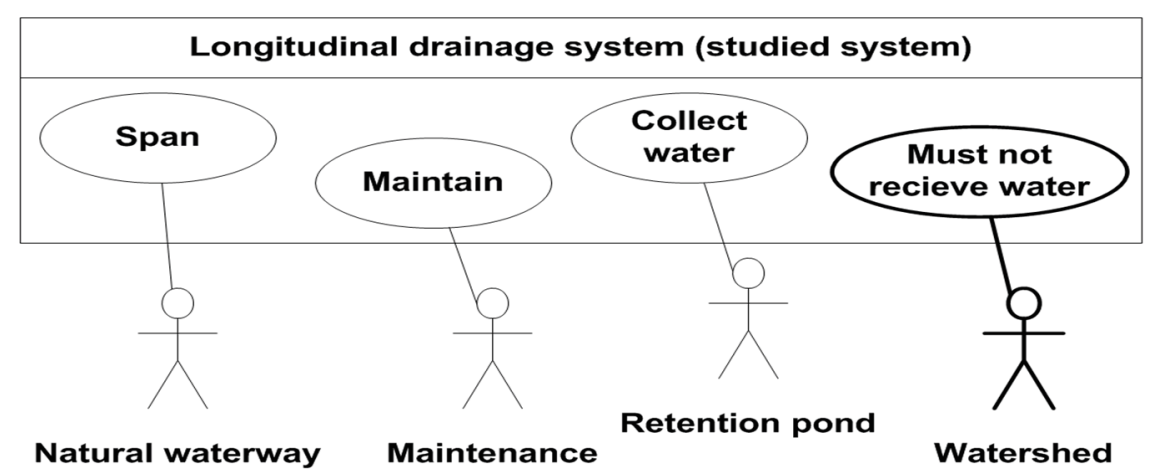

Figure 5: UML use cases of the longitudinal drainage system and its environment; operational vision. 
Table 2: example of the application of the three visions of system engineering on the longitudinal drainage system of a road project, to reach the one of the watershed operational requirements.

\begin{tabular}{|c|c|c|}
\hline External system & Operational requirement & Related system or object \\
\hline Natural waterways & $\begin{array}{l}\text { The flows of permanent or temporary watercourses shall not } \\
\text { enter the longitudinal drainage network for any centenal flood }\end{array}$ & \multirow{4}{*}{$\begin{array}{l}\text { Longitudinal drainage } \\
\text { system }\end{array}$} \\
\hline retention pond & $\begin{array}{l}\text { The retention pond must receive all the rejects from the } \\
\text { longitudinal network }\end{array}$ & \\
\hline maintenance & $\begin{array}{l}\text { Maintenance must be able to maintain the network in } \\
\text { operational conditions }\end{array}$ & \\
\hline \multirow[t]{5}{*}{ watershed } & $\begin{array}{l}\text { The natural watershed must not receive the waters of the } \\
\text { longitudinal network whatever the conditions of rainfall, up to } \\
\text { centenale }\end{array}$ & \\
\hline & Functional vision (functions and systems) & Related system or object \\
\hline & $\begin{array}{l}\text { The longitudinal drainage system must be able to carry a flow for } \\
\text { Q25 }\end{array}$ & $\begin{array}{l}\text { Longitudinal drainage } \\
\text { system }\end{array}$ \\
\hline & Organic vision (physical architecture) & Related system or object \\
\hline & $\begin{array}{l}\text { The longitudinal drainage network must consist of a pipe that } \\
\text { allows flow Q25 }\end{array}$ & $\begin{array}{l}\text { Piping (part of longitudinal } \\
\text { drainage system) }\end{array}$ \\
\hline
\end{tabular}

\subsection{What about LOX?}

With the system engineering approach applied on the whole project, we define the needs in terms of information modelling (geometrical and non-geometrical information). The abstraction(s) that have a stakeholder on the project is driven by the system engineering approach. Then, LOD (object dimensionality and representation) and LOI (attributes but also meta-data) are used to describe the needed information for each requirement to be processed. We present an extract of our results in the tables below (Error! Reference source not found. for organic requirement "the longitudinal drainage network must consist of a pipe that allows flow Q25" and Table 4 for operational requirement "the retention pond must receive all the rejects from the longitudinal network"). In the dimensionality column, we use PERCEPTORY's pictograms defined in (Larrivée, Bédard, \& Pouliot, 2005) for geospatial information to easily represent the spatial geometry.

These tables bellow describe the modelling needs identified during the projects. These requirements are transcribed as much as possible in the digital models to control each requirement. Error! Reference source not found. partially presents the needs for the management of the interfaces between the road equipment and the longitudinal sanitation, based on our practices during interfaces reviews in project management processes. Table 4 partially presents the needs for the topological representation (not necessarily in 3D) for the control of the network continuity.

This application shows that considering first the product requirements allows defining the relevant modelling of information according to the abstractions. We clearly distinguish modelling needs in geometrical and non-geometrical modelling. According to requirements and abstraction, an object (a pipe for instance here) is modelled in different ways.

However, it is necessary to consider more dimensions (columns in the tables above) in the LOD and LOI to introduce the notions of blur and imprecision for example. Requirements should allow defining the relevant information to use or exchange but also the information that has to be kept from one phase to another. This reflection should also question conceptual data models such as IFC to explore the feasibility of an extended definition of LOX as proposed here. The last point is to complete the BIM Execution Plan 
to allow this information management through requirement management and system engineering approach.

Table 3: example of organic requirement for longitudinal drainage system and object modelling.

\begin{tabular}{cccc}
\hline Object & attributs & dimensionnality & representation \\
\hline pipe & diameter & $\begin{array}{c}\text { black (understanding 3D modelling scene) + } \\
\text { horizontal sign in white } \\
\text { black with white generic marking }\end{array}$ \\
$\begin{array}{c}\text { Gantry (road } \\
\text { sign) }\end{array}$ & I & To visualize implantation \\
\hline
\end{tabular}

Table 4: example of operational requirement for retention pond and drainage object modelling.

\begin{tabular}{cccc}
\hline Object & attributs & dimensionnality & representation \\
\hline $\begin{array}{c}\text { pipe and other elements } \\
\text { of longitudinal drainage system }\end{array}$ & $\begin{array}{c}\text { Membership } \\
\text { system }\end{array}$ & Name, & $\begin{array}{c}\text { Topological } \\
\text { synoptic with } \\
\text { connections to } \\
\text { retention ponds } \\
\text { retention pond }\end{array}$ \\
number & Topological \\
synoptic
\end{tabular}

\section{CONCLUSIONS}

Using system engineering to identify the relevant project information architecture is promising. However, we have seen that it is not easy to apply it in the construction industry. First, industry is unfamiliar with this approach. This is a real change in the way we think and organize information of a project. Then, the strong spatial component of the infrastructures creates an important difference with the projects that traditionally use system engineering: aeronautic, space, software, etc. More similar experiments are to be carried out. In addition, it has proved necessary to use a requirements management tool for their structuring and traceability. Therefore, a conceptual data model must be used to link the requirements to the different project objects: we are currently experiencing PLCS (ISO 10303-239 2005).

Then system and requirements engineering help defining the information modelling needs but is this really the right question to which LOX must answer? LOX could also be defined as a functionality to organise information and not only to help to define information exchange requirements in IDM and MVD. The LOX definition has to be improved. All the more if we introduce ontologies to define project information data model through project phases. 


\section{ACKNOWLEDGMENTS}

The author of this paper would like to thank contributors who participated in this different use cases through MINnD (INteroperable INformation Modeling for sustainable Infrastructures) research project and BIM development project in Egis.

\section{REFERENCES}

Badreau, S. and Boulanger, J.-L. (2014). Ingénierie des exigences. Méthodes et bonnes pratiques pour construire et maintenir un référentiel (Dunod.). Paris.

Bolpagni, M., Luigi, A. and Ciribini, C. (2016). The Information Modeling and the Progression of Data-Driven Projects. In CIB World Building Congress (pp. 296-307). Tampere, Finlande.

Bouzeghoub, M. (2006). Les bases de données et l'IDM. In L'ingénierie dirigée par les modèles, $A$ u delà du MDA (Lavoisier.).

Fiorèse, S. and Meinadier, J.-P. (2012). Découvrir et comprendre l'ingénierie système (Cépaduès.). Collection AFIS (Associations Française d'Ingénierie Système).

ISO 29481-1:2016. (2016). Building information models - Information delivery manual.

ISO 29481-2. (2012). ISO 29481-2 2012 Building Information Modeling - Informations Delivery Manual Part 2: Interaction framework.

Kotonya, G. and Sommerville, I. (1998). Requirements Engineering: Processes and Techniques (John Wiley.).

Kreider, R. and Messner, J. (2015). A model use ontology. In CIB W78. Eindhoven, PaysBas.

Krob, D. (2009). Eléments d'architecture des systèmes complexes. In Gestion de la complexité et de l'information dans les grands systèmes critiques (CNRS Edition).

Larrivée, S., Bédard, Y. and Pouliot, J. (2005). How to Enrich the Semantics of Geospatial Databases by Properly Expressing 3D Objects in a Conceptual Model. Berlin Heidelberg. doi:10.1007/11575863

PAS 1192-2. (2013). Specification for information management for the capital / delivery phase of construction projects using building information modelling.

Penn State. (2011). Building Information Modeling Project Execution Planning Guide. Retrieved from http://bim.psu.edu/

Tarandi, V. (2011). The BIM Collaboration Hub: A model server based on IFC and PLCS for Virtual Enterprise Collaboration. In CIB W78 Sophia Antipolis, France

Tolmer, C. (2016). Contribution à la mise en place d'un modèle d'ingénierie concourante pour les projets de conception d'infrastructures linéaires urbaines : prise en compte des interactions entre enjeux, acteurs, échelles et objets. Paris Est Marne-La-Vallée, Lab'Urba, Equipe Génie Urbain.

Tolmer, C.-E. and Castaing, C. (2016). Information Management for Linear Infrastructures Projects: System Engineering and Data Modeling. In ICCCBE. Osaka, Japon. 